\title{
ESPAÇO E CULTURA: RECORRIENDO LOS CAMINOS DE LO SAGRADO.
}

\section{- CÉSAR EDUARDO MEDINA GALLO ${ }^{1}$}

Candidato a doctor en Geografía por la Universidad Nacional Autónoma de México (UNAM). E-mail: cesar_gallo87@hotmail.com

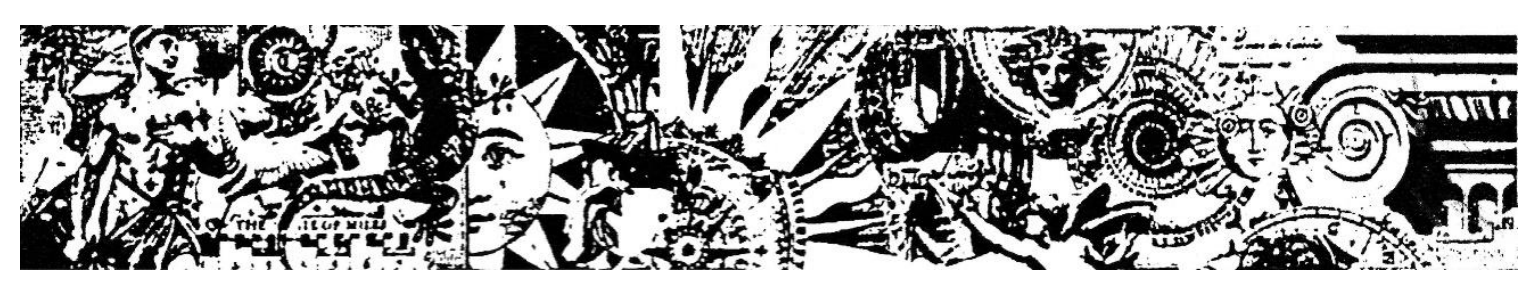

La revista Espaço e Cultura es una publicación editada por la Universidade do Estado do Rio de Janeiro (UERJ), con su primera presentación en 1995, resultado del trabajo de la Dra. Profa. Zeny Rosendahl y el Núcleo de Estudos e Pesquisas sobre Espaço e Cultura (NEPEC), en alianza con el Dr. Roberto Lobato Correa. La revista inicio como un espacio de discusión para la Geografía Cultural brasileña, pero con el paso del tempo, se ha convertido en un referente para dichos temas en el contexto latinoamericano.

Los estudios y trabajos presentados en las publicaciones de la revista Espaço e Cultura son una referencia para el desarrollo de la Geografía Cultural latinoamericana, aunque el país de origen es Brasil, favorece el intercambio de visiones y acercamientos epistemológicos y metodológicos que se realizan desde distintos países pertenecientes a dicha región, como por ejemplo: Argentina, Bolivia, Perú y México. Además cuenta con participaciones de geógrafos anglosajones y europeos como Paul Claval, Don Mitchell, Peter Jackson, Denis Cosgrove, entre otros; lo cual posibilita aún más la discusión entre las diversas perspectivas al interior del campo geográfico. En ese sentido, la revista abre la puerta para el encuentro de las distintas formas en las cuales 
se trabaja la Geografía desde diferentes contextos académicos, institucionales, sociales, políticos y culturales.

Es por esto, que la revista Espaço e Cultura nos lleva a un recorrido por lo sagrado. Esto tanto en un sentido metafórico como real; ya que más allá del estudio de la Geografía Cultural, es un espacio para la discusión de la Geografía de la Religión, la cual es una temática relegada en el ámbito geográfico, pero que toma una importancia y relevancia al situarnos en el contexto latinoamericano. Los estudios sobre religión estuvieron en el foco de diversas disciplinas al interior de las Ciencias Sociales, especialmente la Antropología, Historia y Sociología, donde, recientemente la Geografía poco a poco toma importancia al mantener un diálogo abierto con las disciplinas antes mencionadas. La perspectiva geográfica en estos estudios muestra un amplio panorama, al tomar preceptos epistemológicos de otras disciplinas y encontrarlas en la dimensión espacial de los acontecimientos humanos.

En relación con lo anterior, el estudio de los procesos humanos son percibidos en distintas escalas espaciales y temporales, así como individuales y colectivas, es la comprensión de cómo el ser humano trasciende sus límites personales, comunitarios y sociales, esto es posible por el contacto con elementos que lo hacen superar su propia realidad. A este respecto hago referencia a las palabras que la Dra. Profa. Zeny Rosendahl donde dice: "el ser humano tiene la posibilidad de transcender por tres aspectos: la música, el amor y contacto con el ser supremo mediante sus prácticas religiosas".

La revista es una muestra de la construcción, procesos y avances de la Geografía Cultural brasileña, que ha aportado procedimientos metodológicos y métodos investigativos serios que demuestran la importancia para el avance teórico académico desde la perspectiva cultural, para comprender los fenómenos y relaciones humanas.

Lo anterior es muy importante, en el sentido de la construcción de puentes con otros países latinoamericanos, en el caso de México, la revista ha servido de referencia para la construcción de investigaciones en contextos particulares mexicanos, destacando los avances desde la Geografía Cultural brasileña. Los estudios de la Geografía Cultural en México en general, y en particular en la Universidad Nacional Autónoma de México (UNAM) han sido desvalorizados y poco reconocidos en favor del avance de otros enfoques y construcciones epistemológicas, teóricas y metodológicas en el ámbito de la Geografía, por lo que las aportaciones de los trabajo 
de la revista Espaço e Cultura son una llave para repensar el avance y cómo se trabaja dicha perspectiva en la Geografía mexicana.

En mi caso particular, tuve la oportunidad de tener contacto y trabajar con el grupo de estudios del NEPEC, la Dra. Profa. Zeny Rosendahl y el Dr. Prof. Lobato Correa, el cual sus aportaciones me abrieron camino para mis estudios de posgrado, tanto en maestría como en el doctorado, y tomar en cuenta la fuerza y alcance de las posturas metodológicas y epistemológicas que han avanzado. Asimismo, las publicaciones de la revista y los trabajos de investigación que he realizado han ayudado a estudiantes e investigadores mexicanos a tomar en cuenta y ver la relevancia y la importancia de los estudios de la Geografía Cultural en general, y la Geografía de la Religión, en particular.

En conclusión, la revista Espaço e Cultura ha aportado y ayudado al avance de la Geografía Cultural no sólo en Brasil, sino en México y otros países latinoamericanos, así como en otros ámbitos, alcanzando una escala global. No me queda más que dar mi agradecimiento a todas las personas que han sido parte de tan importante proyecto y muestro mi admiración y apoyo para que el legado de la revista Espaço e Cultura continúe materializándose en éxitos y contribuciones a la Geografía latinoamericana. 